\title{
A multidimensional test of the attributional reformulation of learned helplessness
}

\author{
RICHARD H. ANDERSON \\ Brigham Young University, Provo, Utah \\ KENNETH ANDERSON \\ Harvard Law School, Cambridge, Massachusetts \\ and

\section{DONOVAN E. FLEMING and EDWARD KINGHORN} \\ Brigham Young University, Provo, Utah

\begin{abstract}
In 1978, the original learned helplessness model was critiqued and reformulated by Abramson, Seligman, and Teasdale. Using attributional theory, the reformulation postulated that causal attributions mediate the effects of helplessness according to three dimensions: internalexternal, global-specific, and stable-unstable. The present study was a multidimensional test of the reformulation. Ninety-six subjects were administered identical pretreatments of unsolvable puzzles, and given different reasons for their failure. A later test of solvable anagrams measured cognitive and motivational deficits of helplessness from the pretreatment. Global subjects solved fewer problems than specific subjects. Subjects who were both global and stable solved fewer problems in the test phase than other subjects. The results supported the global-specific dimension and the two-way interaction between the global-specific and the stable-unstable dimensions. The authors conclude that further investigation should elucidate the stable-unstable dimension (perseveration of helplessness deficits over time).
\end{abstract}

The original learned helplessness model was critiqued and reformulated in 1978 by Abramson, Seligman, and Teasdale. Developed largely from infrahuman research, the original hypothesis (Seligman, Maier, \& Solomon, 1971) was found to have at least two major problems: (1) It did not distinguish between cases in which outcomes were uncontrollable for all people and cases in which outcomes were only uncontrollable for some people, and (2) it did not specify when helplessness effects would be general and when specific, or when chronic and when acute (Abramson et al., 1978).

The reformulated model used attribution theory to resolve the above inadequacies. According to the reformulation, once people perceive noncontingency, they attribute their state of helplessness to a cause. If this attribution leads to an expectation of future noncontingency, symptoms of helplessness continue. The nature of this causal attribution may vary along three orthogonal dimensions, defined by Seligman et al. (1971) as internal or external, global or specific, and stable or unstable. The possible combinations of these

Special thanks are due the Behavioral Science Department, California State University, Pomona, for the use of their facilities and technical assistance. Please address correspondence to Richard H. Anderson, 1001 SWKT Brigham Young University, Provo, UT 84602. three dimensions (see Table 1) influence whether helplessness deficits will be chronic or acute, broad or narrow, and whether helplessness will increase depression.

Although attributional theory continues to be mentioned in learned helplessness studies (Seligman, 1980), tests of the reformulated model have been sparse, and results have been equivocal. In one study, Abramson (1979) found support for internal-external attributions (one of the three proposed dimensions) and concluded that such attributions of helplessness were associated with increased depression in learning situations. Campbell (1979) tested the influence of internalexternal attributions on learned helplessness performance deficits and failed to find significant differences among subjects who were given different attributions for failure on learning tasks. Bachus (1979) tested the effect of four causal attributions-luck, effort, task difficulty, and ability -on helplessness deficits and failed to find differences among subjects who held different attributions for failure, and concluded that although attributions may mediate learned helplessness effects, their role is not yet clear.

A weakness shared by previous tests of the reformulated model is that they have tested only one dimension of the model at a time. Since, according to the re- 
formulation, all three proposed dimensions would be presumed to be operating in any situation of helplessness, dimensions not studied were not necessarily left out of the prior experiments-they were simply left uncontrolled. This lack of control may have confounded results and may have been the reason for failure to find differences among treatment groups. A second related weakness of the previous unidimensional studies was their failure to take into account possible interactions between dimensions. For example, a subject who attributed failure to solve anagrams to a lack of ability, and who also believed such inability was likely to persist, might demonstrate greater performance deficits on later tests than would a subject who believed that practice would improve performance on subsequent tests.

The present experiment was a multidimensional test of the reformulation of learned helplessness. It was expected that, if the attributed causes of failure were manipulated, significant differences would be seen in the later performance of learning tasks. Four experimental hypotheses were tested: (1) Global subjects would solve fewer problems in testing than would specific subjects; (2) stable subjects would solve fewer problems than would unstable subjects; (3) there would be a significant global-stable interaction-global-stable subjects would solve fewer problems in testing than would any other subjects; and (4) there would be a significant specificunstable interaction-specific-unstable subjects would solve more problems than would any other subjects.

\section{METHOD}

\section{Subjects}

The subjects were 46 male and 50 female undergraduate students from California State University, Pomona. The subjects were recruited from three sources: 47 came from introductory psychology classes, 26 from engineering classes, and 23 from English classes. The subjects varied in age from 18 to 34 years, with a mean age of 22 years.

\section{Procedure}

The subjects were exposed to identical sets of unsolvable puzzles and asked to provide solutions. Each subject was then given a specific reason for his or her failure; these reasons corresponded to one of eight possible combinations of attributional dimensions suggested by Abramson et al. (see Table 1). Each subject was then asked to provide solutions to a series of solvable anagrams. Three variables with two levels each were tested: internalexternal, global-specific, and stable-unstable. The design was thus a $2 \times 2 \times 2$ factorial. The causal attributions suggested to the subjects as reasons for pretreatment failure were independent variables, and the number of correctly solved anagrams during the test phase constituted the dependent measure.

Pretreatment phase. The subjects were presented with learning discrimination puzzles of a type described in detail by Hiroto and Seligman (1975). Briefly, each problem consisted of $103 \times 5$ cards upon which were drawn some combination of features. The task in each case was to find the consistent feature in all cards. All pretreatment problems were in fact unsolvable; that is, no feature was consistent within any problem set. The pretreatment comprised 10 problems of 10 cards each; all subjects were presented with identical pretreatment puzzles in the same order. All other pretreatment testing conditions were identical for each subject.
Table 1

Combinations of Attributional Dimensions According to Reformulated Model and Corresponding Reasons Suggested to Subjects for Pretreatment Failure by Treatment Group

\begin{tabular}{|c|c|}
\hline Attributional Configuration & $\begin{array}{l}\text { Reason Given to Subject for } \\
\text { Pretreatment Failure }\end{array}$ \\
\hline Internal-Global-Stable & $\begin{array}{l}\text { "Everyone else got these prob- } \\
\text { lems right. Maybe you'ie just } \\
\text { not a good problem solver." }\end{array}$ \\
\hline Internal-Specific-Stable & $\begin{array}{l}\text { "Everyone else got these prob- } \\
\text { lems right. Maybe you're just } \\
\text { not very good at solving some of } \\
\text { these problems." }\end{array}$ \\
\hline Internal-Global-Unstable & $\begin{array}{l}\text { "Everyone else got these prob- } \\
\text { lems right. I don't think you } \\
\text { tried very hard. Most of the } \\
\text { other people took more time } \\
\text { and wrote more on their test } \\
\text { papers." }\end{array}$ \\
\hline Internal-Specific-Unstable & $\begin{array}{l}\text { "Everyone else got these prob- } \\
\text { lems right. I think you were just } \\
\text { unlucky with these particular } \\
\text { problems." }\end{array}$ \\
\hline External-Global-Stable & $\begin{array}{l}\text { "No one else got these problems } \\
\text { right either. Actually, all of } \\
\text { these problems are unsolvable." }\end{array}$ \\
\hline External-Specific-Stable & $\begin{array}{l}\text { "No one else got these problems } \\
\text { right either. Actually, some of } \\
\text { these problems are unsolvable." }\end{array}$ \\
\hline External-Global-Unstable & $\begin{array}{l}\text { "No one else got these problems } \\
\text { right either. Problems of this } \\
\text { type are very tricky and hard to } \\
\text { solve." }\end{array}$ \\
\hline External-Specific-Unstable & $\begin{array}{l}\text { "No one else got these problems } \\
\text { right either. All of these prob- } \\
\text { lems can be solved, but I just } \\
\text { think we chose an unlucky set } \\
\text { of problems." }\end{array}$ \\
\hline
\end{tabular}

Assignment of treatment condition. Pretreatment problems were scored in the subject's presence, and every subject was informed that all answers were wrong. The experimenter then verbally transmitted a "likely" reason to the subject for his or her failure. These suggested reasons are listed in Table 1 and correspond to the eight treatment groups. The suggested attributions were presented word for word as they appear in Table 1 , in a manner to convince the subjects that the reasons given were the actual causes of pretreatment failure.

Test phase. Immediately after having been informed of the "reason" for pretreatment failure, the subjects were presented a series of 10 five-letter anagrams similar to those used by Hiroto and Seligman (1975) in order to identify motivational and cognitive deficits. Examples of anagrams used are the following: (1) BLOEN, (2) RNUTB, and (3) BOARL. The subjects were asked to rearrange each anagram into a recognizable word. The correct letter-order response for all anagrams was the same: $5-3-1-2-4$. The anagrams were painted in black ink on $3 \times 5$ cards, one anagram per card. All subjects attempted to solve an identical set of 10 anagrams, and the test conditions for all subjects were identical.

Following the attempt to solve the test-phase anagrams, the subject was asked to respond to a questionnaire listing possible reasons why he or she could have failed the pretreatment. These reasons corresponded to the attributional configurations listed 
Table 2

Mean Cell Scores and Standard Deviations (SDs) for Number of Test-Phase Anagrams Solved Correctly by Treatment Group

\begin{tabular}{|c|c|c|c|c|c|c|c|c|}
\hline & \multicolumn{4}{|c|}{ Stable } & \multicolumn{4}{|c|}{ Unstable } \\
\hline & \multicolumn{2}{|c|}{ Global } & \multicolumn{2}{|c|}{ Specific } & \multicolumn{2}{|c|}{ Global } & \multicolumn{2}{|c|}{ Specific } \\
\hline & Mean & SD & Mean & SD & Mean & $\mathrm{SD}$ & Mean & SD \\
\hline & 4.33 & 2.42 & 8.67 & 1.2 & 5.80 & 1.92 & 7.40 & 1.14 \\
\hline External & 1.80 & 2.49 & 8.20 & 2.47 & 4.40 & 3.21 & 8.83 & 1.94 \\
\hline
\end{tabular}

in Table 1. This questionnaire served as a manipulation check on the amount of internalization of the suggested attributions.

\section{RESULTS}

Performance was assessed by the number of puzzles correctly solved during the test phase. Table 2 presents mean scores and standard deviations of each of the eight treatment groups. Cell means ranged from 1.8 for the external-global-stable condition to 8.93 for the externalspecific condition.

Analysis of variance (ANOVA) showed a significant main effect along the global-specific dimension $[\mathrm{F}(3,14)$ $=39.44, \mathrm{p}<.00001]$. The subjects given global causes for failure (e.g., "No one else got these problems right either") had lower mean scores than the subjects to whom specific causes for failure were suggested (e.g., "Everyone else got these problems right"). One of the interactions-the global-specific/stable-unstable interaction-was significant $[F(4,12)=3.37, p<.02]$. The three-way interaction between the global-specific/ internal-external/stable-unstable dimensions was not significant.

The manipulation check given at the end of the test phase showed extremely good agreement between suggested and internalized attributions. Only 4 of 96 subjects reported a different causal attribution in accounting for their pretreatment failure. A recalculation of cell means and ANOVA without these subjects showed no significant difference in results.

The results confirm Hypothesis 1: The Global subjects solved fewer problems than the specific subjects. That is, the subjects told that all pretreatment problems were unsolvable solved fewer anagrams in the test phase than subjects who were told that only some of the pretreatment problems were unsolvable. Hypothesis 3 was also supported: The subjects who were both global and stable solved fewer problems than any other subjects. Because ANOVA showed no other F scores to be significant, Hypotheses 2 and 4 must be rejected in this study.

\section{DISCUSSION}

It is clear that attributions do play a role in learned helplessness. This conclusion differs from the outcomes reached by Bachus (1979) and Campbell (1979), neither of whom found support for attributions in helplessness deficits; however, these differences may be explained in part by differences of methodology. Bachus tested attributions, but his treatment groups were nondimensional. The strength of the Abramson et al. (1978) model lies in its ability to differentiate attributions dimensionally. Campbell's study did test attributions dimensionally, following the Abramson et al. (1978) reformulation, but in addition to failing to support attributions mediating helplessness deficits, Campbell's study failed to support learned helplessness in general-no significant differences were found between treatment groups.

Our results support Abramson's (1979) suggestion that attributions determine the generality of helplessness deficits. When reasons for failure are attributed to global causes, helplessness is likely to be general and to occur across a variety of situations, and when reasons for failure are attributed to specific causes, helplessness is likely to occur only in situations identical to or highly similar to the original situation. This study failed to support the stable-unstable and internal-external dimensions. The stable-unstable dimension would be expected to mediate the perseveration of learned helplessness deficits over time. Although we found no evidence supporting time-related attributions, timedependent characteristics of causal attributions of helplessness should exist if attributions play a role in learned helplessness, and need to be explored in further study.

\section{REFERENCES}

Abramson, L. (1979). Universal versus personal helplessness: An experimental test of the reformulated theory of learned helplessness and depression. Unpublished doctoral dissertation, University of Pennsylvania, Philadelphia, PA.

Abramson, L., Seligman, M. E. P., \& Teasdale, J. D. (1978). Learned helplessness in humans, critique and reformulation. Journal of Abnormal Psychology, 87, 49-74.

BACHUS, C. T. (1979). The role of causal attributions in the mediation of learned helplessness (Doctoral dissertation, Catholic University of America, Washington, DC, 1979). Dissertation Abstracts International, 39, 6106B-6107B.

CAmpbell, H. E. (1979). The influence of attributions on learned helplessness performance deficits (Doctoral dissertation, Fordham University, Bronx, NY, 1979). Dissertation Abstracts International, 39, 5539B.

Hiroto, D. S., \& Seligman, M. E. P. (1975). Generality of learned helplessness, in man. Journal of Personality and Social Psychology, 31, 311-327.

Seligman, M. E. P., \& Weiss, J. M. (1980). Coping behavior: Learned helplessness, physiological change, and learned activity. Behavior Research and Therapy, 18, 457-512.

Seligman, M. E. P., Maier, S. F., \& Solomon, R. L. (1971). Unpredictable and uncontrollable aversive events. In F. R. Brush (Ed.), Aversive conditioning and learning. New York: Academic Press.

(Manuscript received for publication January 23, 1984.) 